\title{
Modeling and Simulation of Heat Transfer Phenomenon Related to Mold Heating during Investment Casting
}

\author{
Muhammad Musaddique Ali Rafique ${ }^{1,2^{*}}(\mathbb{D})$, Umair Shah ${ }^{3}$ \\ ${ }^{1}$ Department of Metallurgical and Materials Engineering, University of Engineering and Technology, Lahore, Pakistan \\ ${ }^{2}$ Eastern Engineering Solutions LLC, Detroit, MI, USA \\ ${ }^{3}$ College of Engineering \& Emerging Technologies, University of the Punjab, Lahore, Pakistan \\ Email: ali.rafique@hotmail.com
}

How to cite this paper: Rafique, M.M.A. and Shah, U. (2020) Modeling and Simulation of Heat Transfer Phenomenon Related to Mold Heating during Investment Casting. Engineering, 12, 291-314. https://doi.org/10.4236/eng.2020.125024

Received: May 11, 2020

Accepted: May 24, 2020

Published: May 27, 2020

Copyright ( 2020 by author(s) and Scientific Research Publishing Inc. This work is licensed under the Creative Commons Attribution International License (CC BY 4.0).

http://creativecommons.org/licenses/by/4.0/ (c) (i) Open Access

\begin{abstract}
Cast shape during investment casting process dictates properties and service life of the casting. These properties are the function of cast part parameters (both static and dynamic), part geometry and hence mold geometry, nature and type of metal being cast, properties (extrinsic and intrinsic) and processing parameters (rate of heating, rate of cooling, rate of pouring). Improper and inadequate manipulation and modification of mold properties degrade the properties and life of casting altogether. A mathematical model is developed using standard transport equations incorporating all heat transfer coefficients (HTCs) to determine the effect of external mold heating on the properties of the final casting and a simulation is performed in $\mathrm{C}++$ to validate it against experimental results. Pure iron is casted in investment molds of silica sand with zircon coating. Airflow near the mold surfaces was partially restricted due to geometry of the molds and arrangement of the pieces around a tree. The variations in heat transfer coefficient contribute towards total heat transfer out of mold surface. External heating is found to be very effective for improved casting properties. The mold heat transfer profile is found to be in good agreement with experimental values validating the effectiveness of mold heating.
\end{abstract}

\section{Keywords}

Investment Casting, Mold, HTC, C++, Simulation

\section{Introduction}

The investment casting process is capable of producing complex castings by 
pouring metal into a mold, created as a result of melting and pouring out of wax pattern (dewaxing) from a ceramic coated body at high temperature [1]. The shape left adopts the shape of casting. The wax pattern is formed at an earlier stage by injecting cold wax in a metal die precisely carrying the shape of part to be casted. It is two-step replication process in which wax pattern and subsequently metal parts are produced [1]. The dimensional difference between the wax pattern and casted metal is due to the solidification shrinkage of metal, wax and shell molding materials. The differences between wax pattern and die, and between final part and shell, are known as shrinkage allowances of wax and metal, respectively. These allowances are considered during design and are important for successful investment casting process. Time taken for solidification is one of the most important factors governing quality of casting and is in direct relation with shrinkage and liquid to solid state transformation of alloy in mold cavity [1]. It can be controlled by many factors such as melt chemistry, superheat, cooling rate, mold material chemistry, mold geometry and mold surface heating. Mold heating is the single most important extrinsic physical factor influencing the casting process. It can not only control heating rate but also influence many metallurgical and mechanical properties of castings such as porosity, shrinkage, hot tearing, lapping, segregation, surface roughness and variation of properties across transverse profile of casting [1] [2]. Mold heating can be controlled by winding coil (e.g. nichrome wire) around a ceramic insulator (heating element) and placing these elements around the ceramic shell at a certain fixed distance in a metal fixture. The space in between elements is covered by soft insulating material (e.g. glass wool) to reduce the heat loss to environment and maximize heat efficiency. The heating of elements is controlled by alternating source via numerical controller. The effect of heating on mold can be studied by heat transfer and deformation analysis during the pouring and solidification in mold cavity [3]. In this paper, numerical simulation of heat transfer phenomena during investment casting process is discussed to investigate the effect of mold heating. Shell molds are considered anomalous to packed bed of sintered ceramic particles having different sizes and shapes [4]. The semi-transparent effects in the silica at high temperatures enhance the heat transfer ability of sand, incorporated in our work by a temperature-dependent thermal conductivity in numerical modeling and simulation [5]. For shell molds made up of silica with a zircon coat, data on relevant properties is reported in earlier studies [5] [6]. Previously, in most studies on numerical simulation of casting processes [7]-[13], a set of constant heat transfer coefficients are used to determine the heat flow from metal to mold. Whereas in actual situation, heat transfer coefficients (HTCs) change continuously during casting due to change in casting conditions (heating of air, mold and surrounding) [3]. All these studies suffered from drawback of not incorporating these transient conditions in casting process, which affect the rate of heat transfer and mold heating. Anderson et al. [14], found that the use of single HTC for all mold surfaces was inaccurate. Major 
contribution of present study is to determine HTCs based upon transience of system as well as incorporating incremental changes in HTCs during solidification back into the initial calculations using iterative approach in programming. This approach gives better estimates of actual heating profile across mold surface. Cooling conditions at shell mold surface were determined by the airflow pattern and through heat dispensing. Some shell surfaces were kept open to natural convection, while others were partially open, while some were affected by the proximity and geometry of nearby surfaces. Thus, the heat transfer conditions at each mold surface depend upon the surface length scale, configuration and surface position in the casting tree [3]. Shell emissivity is determined from experimental data [5] [6]. Temperature of the shell was measured using different thermocouple arrangements around tree. A model is developed and computer simulations of model is carried out in C++ using iterative approach on constitutive equations for the heat transfer coefficients based on correlations developed for conduction, convection and radiation [15]. Castings were poured at two independent foundries, Steel Castings (Pvt.) Ltd., Gujranwala, and at Foundry Lab, KRL Pakistan to provide sufficient experimental data and ensure consistency. Computer simulation results agree with experimental data, validating the model. A computer simulation-based model recommended and presented for predicting heat transfer profile across mold surface as affected by power given to heating elements, nature, amount and type of insulating material, distance of heating elements from mold, positioning and configuration of heating elements around mold and, associated heat transfer phenomena of metals and alloys.

\section{Mathematical Formulation}

To study the effect of mold heating on the properties of casting, a mathematical model is developed. Translation of mathematical equations governing the heat transfer phenomena into a model and then its simulation was adopted as solution strategy. To formulate a generalized mathematical model corresponding to heat transfer phenomena during solidification of metals and alloys in mold, following assumptions were made:

1) Mold is made up of one unit consisting of one central runner (down sprue) and associated tree geometry.

2) Mold is heated to higher temperature internally (pouring temperature of metal) at once.

3) Main source of external mold heating is electrical resistance heating (heating elements).

4) Heating elements remain at constant temperature (after reaching their peak temperature).

5) Heating elements are in contact with mold's outermost wall.

6) Temperatures of outer most mold wall and heating elements (peak temperature) are same.

7) Thermal properties of mold are not constant and function of change in tem- 
perature (during heating (by heating elements) and cooling/solidification of metal).

8) Thermal properties of heating elements are not constant and are a function of change in temperature.

9) Thermal conductivity of mold is very low.

10) Major portion of heat is lost through open atmosphere.

Based upon preceding assumptions, following is considered:

1) Downsprue and cubical pieces attached to it are considered similar in configuration to an open ladle in which, mode of heat transfer is

a) convection and radiation from top and

b) conduction through walls.

\subsection{Heat Transfer for Investment Casting Shell}

In order to formulate a mathematical model for heat transfer problem (heating of mold by external heater and hot metal) during casting, consider superheated liquid metal poured in an investment casting shell. There are two main separate, independent paths in which heat transfer occurs.

1) Path 1: in which electrical power is used to heat the resistance elements to desired temperature. This further consists of two sub steps.

a) First step in which temperature of heating elements is raised to high temperature.

b) Second step during which heat generated as a result is used to heat mold.

2) Path 2: in which hot metal loses its heat which becomes the source of heating of mold. This further consists of two sub steps.

a) First step in which metal losses its sensible heat (superheat).

b) Second step during which metal losses its heat of fusion $\left(H_{f}\right)$.

Heating of mold and heat transfer profile across mold wall is governed independently by mechanism of heating in each path. Path 1 is heating of resistance elements and production of heat. It is governed by electrical characteristics (electricity (voltage rating, current, power, power factor), heating element (geometry (shape, size), material)) and type of calculations (resistance heating) while in Path 2, heating is determined separately during each interval (sub step) using different heat transfer coefficients (HTCs) and then effects of heating are summed up together to get total constituted effect of mold heating i.e. (a) time in which heating elements gets heated to their peak temperature to heat mold and (b) time in which molten metal heat the mold while cooling down from its melting point (solidification). This has significant effect on factors such as time in which heaters (heating elements) gets heated to their peak temperature and effect of preheated mold on; rate of decrease of metal temperature, mold surface temperature, content of heat (released and contained), rate of heat transfer, thermal resistance and conductance of mold (during solidification), and holding time (duration).

\subsubsection{Path 1: Heating of Resistance Heating Elements-Heat Generation} When power to mold heaters is switched ON, electricity starts flowing through 
the circuit. The materials of wire (e.g. nichrome) offers resistance to the flow of current and thus metal starts picking up heat, mold heater gets hot and heat energy is produced. This heat energy is transferred to surroundings and to mold shell outer surface by convection and radiation.

Consider a Voltage, $V$ flowing through resistor of resistance, $R$ in time $t$, then energy (heat) generated may be written as [16]

$$
\begin{gathered}
Q_{t}=V I t \\
Q_{t}=\frac{V^{2}}{R} t
\end{gathered}
$$

where $Q_{t}=$ Quantity of power consumed (Watt - hour) \& heat energy produced (kJ), $V=$ Voltage (volts) (standard, different for different localities), $R=$ Resistance of heating element (ohms) (depend on cross sectional area, length \& electrical resistivity of material changes with change of temperature) [9], time $=$ Time of heating (hours).

All the heat generated in this path goes into overcoming material heat losses expressed in terms of specific heat capacity of substance when it is heated across a temperature difference. This may be written as [14] [17]

$$
\begin{gathered}
Q_{t}=m C_{p} \Delta T \\
Q_{t}=m C_{p}\left(T_{2}-T_{1}\right)
\end{gathered}
$$

where $m=$ Mass of heating element $(\mathrm{kg}), C_{p}=$ Specific heat capacity of material (function of temperature) $(\mathrm{kJ} / \mathrm{kg} \mathrm{K})[8], T_{2}=$ Final temperature $(\mathrm{K}), T_{1}=$ Initial temperate $(\mathrm{K})$.

$$
\text { Comparing (2) and (3) }
$$

$$
\begin{gathered}
m C_{p}\left(T_{2}-T_{1}\right)=\frac{V^{2}}{R} t \\
t=m C_{p}\left(T_{2}-T_{1}\right) \times \frac{R}{V^{2}}
\end{gathered}
$$

This is the time in which elements reaches set operating temperature $\left(T_{2}\right)$ from initial temperature $\left(T_{1}\right)$. Putting back the calculated time in (2) yields energy (heat) generated (hence available for transfer to raise the temperature of mold and its surrounding).

Various factors affect time of heating during Path 1 such as thermal conductivity of mold material, heating conditions, maximum power rating of heating elements, geometry of heating elements, material of heating elements, safe operating limit, and specific heat of metal. All these should be taken into account while designing a heating system [15] [18]. Soon after the element is heated to designated temperature, metal is poured and second Path of heating (heat transfer) begins.

\subsubsection{Path 2: Heating of Mold (Heat Transfer)}

This is the step in which heating of mold starts as hot metal at high temperature is poured in it. Heating of mold (externally) and pouring of metal are 
synchronized in such a way as both meet at one point and minimum or no time delay exist between them (i.e. as soon as mold is heated to its peak temperature, metal is ready for pouring). Since metal takes a lot of time to reach its melting point and then superheating is done along with alloying and homogenization, usually mold heating is not started until very last minute of castings i.e. mold heaters are started only during last minutes of pouring. This is also advantageous in a sense that mold, which is enclosed in closed chamber take advantage of heat from liquid pool of metal from crucible of furnace thus reducing the heat necessary to heat itself essentially by external heating elements. It also protects it from any thermal shock that may be created and any high temperature structural disintegration (shape loss of ceramic). Hot metal loses its heat in two distinct steps;

1) Loss of sensible heat of metal and associated heat transfer - first step of solidification

When metal is poured in investment casting shell, whole of the shell is quickly heated to high temperature (temperature of molten metal) from inside. Heat transfer also starts consequently immediately, and temperature of metal starts decreasing. As a result of this, temperature of mold starts increasing. During this step total heat transfer from top and walls is [19]

$$
Q_{t}=Q_{T} \times t_{1}
$$

where $Q_{t}=$ Total quantity of heat lost from top and walls, $Q_{T}=$ Total rate of heat transfer by convection and radiation from top and conduction through walls and $t_{1}=$ Total time taken for heat transfer (time of solidification in first step).

Heat transfer occurs by three modes namely convection, conduction and radiation; total rate of heat transfer $\left(\mathrm{Q}_{\mathrm{T}}\right)$ is summation of rate of heat transfers by each mode

$$
Q_{T}=Q_{T 1}+Q_{T 2}+Q_{T 3}
$$

where $Q_{T 1}, Q_{T 2}, Q_{T 3}$ are the rate of heat transfers by convection and radiation from top surface, conduction through walls and convection and radiation from heated mold outer surface, respectively.

Rate of heat transfer by convection and radiation from top may be written as:

$$
Q_{T 1}=\left(h+h_{r}\right)_{\bar{T}} \cdot A_{T} \cdot\left(\bar{T}-T_{\infty}\right)
$$

where $\bar{T}=\frac{1}{2}\left(T_{p}+T_{m}\right)$, temperature at which heat transfer coefficients (HTCs) are determined, $h$ and $h_{r}$ are the heat transfer coefficients for free convection and radiation, respectively, $A_{T}$ is area of top surface of mold and $T_{\infty}$ is mold temperature. Major portion of heat in this process of heat transfer is lost through top surface thus $Q_{T 1}$ is the major rate of heat transfer during solidification. This is the reason; risers of castings are usually covered by some insulating compound or bad heat-conducting medium to keep metal liquid for a longer period of time so that proper feeding of metal could be achieved [1].

Rate of heat transfer by conduction may be written as: 


$$
Q_{T 2}=\frac{T_{p}-T_{\infty}}{R_{t}}
$$

where $T_{p}$ and $T_{\infty}$ are the inside and outside temperatures of the mold and $R_{t}$ is the thermal resistance of the mold wall.

Thermal resistance of the mold here though very high, is not constant, but keeps on changing with change of temperature and contributes towards overall effect of heat transfer [3].

Similarly, rate of heat transfer again by convection and radiation from outer heated wall of mold may be written as:

$$
Q_{T 3}=\left(h+h_{r}\right)_{T_{s}} \cdot A \cdot\left(T_{s}-T_{\infty}\right)
$$

where $T_{s}$ is the surface temperature of the mold. $T_{\infty}$ is the outside (surrounding) temperature of the mold [ $\left(T_{\infty}=T_{r}\right) . T_{r}=$ room temperature]. $h$ and $h_{r}$ are the heat transfer coefficients (HTCs) for free convection and radiation, respectively, and $A$ is the area of heated mold surface towards ambient. This mode of heat transfer has very little contribution towards overall rate of heat transfer during first step, as surface of mold is already at high temperature (mold heater temperature) and seldom gets heated to a high value thus almost no heat transfer occur which is the objective of present study as well. This is beneficial in a sense that molten metal does not encounter a cold surface of the mold thus surface defects (cold shuts, surface roughness, surface laps, hot tearing) are entirely, or to a large extent, removed which is desirable. This also has little contribution due to high thermal resistance of mold material(s), which stops most of heat from coming out of the mold and since mold is already at high temperature this factor is further diminished [3].

Putting back values in Equation (7)

$$
Q_{T}=\left(h+h_{r}\right)_{\bar{T}} \cdot A_{T} \cdot\left(\bar{T}-T_{\infty}\right)+\frac{T_{p}-T_{\infty}}{R_{t}}+\left(h+h_{r}\right)_{T_{s}} \cdot A \cdot\left(T_{s}-T_{\infty}\right)
$$

Total quantity of heat transferred $\left(Q_{t}\right)$ is actually the heat lost by the metal as its sensible heat, which may be written as [1]

$$
\begin{gathered}
Q_{t}=m \cdot C_{p} \cdot \Delta T \\
Q_{t}=m \cdot C_{p} \cdot\left(T_{p}-T_{m}\right)
\end{gathered}
$$

where $C_{p}$ is the specific heat of metal, $T_{p}$ and $T_{m}$ are the pouring and melting temperatures of the metal respectively and $m$ is the mass of the metal being poured.

Combining Equations (11) and (12) and putting values in Equation (6)

$$
\begin{aligned}
& m \cdot C_{p} \cdot\left(T_{p}-T_{m}\right) \\
& =\left[\left(h+h_{r}\right)_{\bar{T}} \cdot A_{T} \cdot\left(\bar{T}-T_{\infty}\right)+\frac{T_{p}-T_{\infty}}{R_{t}}+\left(h+h_{r}\right)_{T_{s}} \cdot A \cdot\left(T_{s}-T_{\infty}\right)\right] \cdot t_{1} \\
& t_{1}=\frac{m \cdot C_{p} \cdot\left(T_{p}-T_{m}\right)}{\left(h+h_{r}\right)_{\bar{T}} \cdot A_{T} \cdot\left(\bar{T}-T_{\infty}\right)+\frac{T_{p}-T_{\infty}}{R_{t}}+\left(h+h_{r}\right)_{T_{s}} \cdot A \cdot\left(T_{s}-T_{\infty}\right)}
\end{aligned}
$$


This is the expression for the calculations of time for solidification of metal during pouring and subsequent freezing in investment casting molds during step in which its losses all its sensible heat (first step of solidification).

Various factors affect this time of solidification during first step such as thermal conductivity of mold material, casting conditions, pouring temperature and specific heat of metal of which mold heat is one. It is by far the most important and effective extrinsic factor as it is possible to control heat from outside which in turn control and govern heat transfer and subsequently the properties of casting. This, along with others, should be taken into account while designing a casting process [2]. Soon after the release of all superheat of metal, second step of solidification begins.

2) Loss of heat of fusion of metal and associated heat transfer - second step of solidification

When metal loses all its sensible heat (superheat) and reaches its melting temperature, a phase transformation occurs, and metal starts losing heat as heat of fusion $\left(H_{f}\right)$. This heat transfer continues till whole of the metal solidifies in the mold. This is second step of heat transfer [1].

Like first step of heat transfer, heat again transfers in three modes namely convection, conduction, and radiation. This occurs in a fashion very similar to first step of heat transfer (i.e. from top, walls and heated surface of mold). Thus, total heat transfer from top and walls may be written as

$$
Q_{t}=Q_{T} \cdot t_{2}
$$

where $Q_{t}$ is the total quantity of heat lost from top and walls, $Q_{T}$ is the total rate of heat transfer by convection and radiation from top and conduction through walls and $t_{2}$ is the total time taken for heat transfer (time of solidification in second step).

Again, total rate of heat transfer is the summation of rates of heat transfer by individual modes

$$
Q_{T}=Q_{T 1}+Q_{T 2}+Q_{T 3}
$$

where $Q_{T 1}, Q_{T 2}, Q_{T 3}$ are the rate of heat transfers by convection and radiation from top surface, conduction through walls and convection and radiation from heated mold surface respectively.

Quantities $Q_{T 1}, Q_{T 2}$ and $Q_{T 3}$ may be determined by use of Equations (8)-(10) with replacement of $\bar{T}$ with $T_{m}$ in Equation (8) as this is the temperature at which HTCs are determined during second step and $T_{p}$ with $T_{m}$ in Equation (9) as this is the reference temperature from which heat is transferred during conduction in second step.

When values are inserted into Equation (15) following is obtained

$$
Q_{T}=\left(h+h_{r}\right)_{T_{m}} \cdot A_{T} \cdot\left(T_{m}-T_{\infty}\right)+\frac{T_{m}-T_{\infty}}{R_{t}}+\left(h+h_{r}\right)_{T_{s}} \cdot A \cdot\left(T_{s}-T_{\infty}\right)
$$

In second step, total quantity of heat transferred $\left(Q_{t}\right)$ is the heat lost by metal as its heat of fusion, which may be written as [14] 


$$
Q_{t}=m H_{f}
$$

where, $H_{f}$ is the heat of fusion of metal and $m$ is the mass of metal.

Putting values from Equations (16) and (17) in (14)

$$
\begin{gathered}
m H_{f}=\left[\left(h+h_{r}\right)_{T_{m}} \cdot A_{T} \cdot\left(T_{m}-T_{\infty}\right)+\frac{T_{m}-T_{\infty}}{R_{t}}+\left(h+h_{r}\right)_{T_{s}} \cdot A \cdot\left(T_{s}-T_{\infty}\right)\right] \cdot t_{2} \\
t_{2}=\frac{m H_{f}}{\left(h+h_{r}\right)_{T_{m}} \cdot A_{T} \cdot\left(T_{m}-T_{\infty}\right)+\frac{T_{m}-T_{\infty}}{R_{t}}+\left(h+h_{r}\right)_{T_{s}} \cdot A \cdot\left(T_{s}-T_{\infty}\right)}
\end{gathered}
$$

This is the expression for calculation of time of solidification of metal during the interval when it transforms from liquid to solid state i.e. time when metal losses all its heat of fusion at its melting point. Factors affecting time of solidification during this step are heat of fusion of metal, melting point, thermal conductivity of mold, cooling conditions outside mold, surface area of mold exposed to ambient and the extent to which mold is heated during first step [2].

Finally, adding Equations (13) and (18) yields the final expression for calculating the time of solidification during whole period from liquid to solid.

$$
t=t_{1}+t_{2}
$$

Most important objective in most engineering applications is to achieve a rapid rate of heat transfer (chilling) as it facilitates fine grain structure in metal which imparts strength and hardness to metal/alloy. This rapid rate of heat transfer may be achieved by use of mold materials with high thermal conductivity, forced convection conditions (blowing of air on the outer surface of the mold) or rapid cooling of mold surfaces (sprinkling of water on outer mold surface). This rapid rate of heat transfer however, can induce brittleness in alloy along with poor impact properties. Slow rate of heat transfer on the other hand, can induce problems of segregation especially predominant in multicomponent alloys, long columnar grains and softness that are detrimental to its further applications [1]. So, in most practical conditions an optimum rate of heat transfer is desirable which should facilitate a high strength, fine-grained material with good mechanical properties. In most of the cases, this is achieved in conjunction with post casting heat treatment [1] [2].

\subsection{Determination of Heat Transfer Coefficient (HTC's)}

Determination of coefficients of heat transfer is one of the most important steps in determining rates of heat transfer during solidification. These HTCs depend upon various dimensionless numbers, which depend on geometry, configuration, and shape of casting. These are described below.

\subsubsection{Heat Transfer Coefficient for Free/Natural Convection}

HTC for free/natural convection $(h)$ is given by Nusselt Number $(\mathrm{Nu})$

$$
N u=C\left(G_{r} \cdot P_{r}\right)^{m}
$$


where $C$ and $m$ are constants [3], $P_{r}$ and $G_{r}$ are Prandtl and Grashof numbers, respectively. [( $\left.G_{r}=\frac{g \beta \rho^{2}\left(T_{0}-T_{\infty}\right) L^{3}}{\mu^{2}}\right), g$ is gravitational constant, $\beta=\frac{1}{T}, T$ is film temperature, $\rho$ is density, $\mu$ is viscosity, and $L$ is characteristic length), ( $P_{r}=\frac{C_{p} \mu}{k}, C_{p}$ is heat capacity, $\mu$ is viscosity and $k$ is thermal conductivity), [18] also

$$
N u=\frac{h \cdot L}{k}
$$

where $h$ is HTC for free/natural convection, $L$ is characteristic length ( $L=\frac{A}{P}, A$ is area, $p$ is perimeter) and $k$ is thermal conductivity of metal/alloy [4].

Combining Equations (20) and (21)

$$
h=\frac{C\left(G_{r} \cdot P_{r}\right)^{m} \cdot k}{L}
$$

This is expression for generalized HTC for free/natural convection. This, however, vary as configuration of casting changes. This is briefly described as follows.

1) For spaces fully open to air (such as top mold surface, surface of wall of mold)

For these surface, Nusselt number may be expressed in terms of Rayleigh number $\left(R a_{L}\right)$ as

$$
\begin{gathered}
N u=0.54 R a_{L}^{1 / 4} \\
N u=0.27 R a_{L}^{1 / 4} \\
N u=0.68+0.515 R a_{L}^{1 / 4}
\end{gathered}
$$

where $R a_{L}=\frac{g \beta\left(T_{s}-T_{\infty}\right) L^{3}}{v \alpha}$ in this, $g=$ gravitational acceleration, $\beta=$ thermal expansion coefficient, $v=$ kinematic viscosity of fluid, $L=$ characteristic length scale, and $\alpha=$ thermal diffusivity. Equations (23) and (24) describe the correlation for the cooling of a horizontal surface facing upward and downward respectively. Equation (25) is for vertical surfaces. This expression may be modified to account for inclined surfaces such that $R a_{L}$ is evaluated considering the gravitational acceleration component parallel to wall [4].

\section{2) For spaces partially open to airflow (such as spaces between cubes)}

For these types of situations, correlation for a "two plate" configuration may be used. Thus, equation for a Nusselt number for a channel between two plates is;

$$
N u_{s}=\frac{1}{24} R a_{s}\left(\frac{S}{L}\right)\left(1-\exp \left[\frac{-35}{R a_{s}} \frac{L}{S}\right]\right)^{3 / 4}
$$

where $S$ = distance between two plates and Rayleigh number us calculated based on $S$. 


\subsubsection{Heat Transfer Coefficient for Radiation}

HTC for radiation heat transfer depends upon temperature, emissivity of molten metal and emissivity of heated mold material for both steps of heat transfer and is given by modification of Stefan-Boltzmann law of thermal radiation [8], which may be written as

$$
h_{r}=\varepsilon \sigma\left(T_{1}^{2}+T_{2}^{2}\right)\left(T_{1}+T_{2}\right)
$$

where, $\varepsilon$ is emissivity of molten metal, and heated mold material in both forms in which heat is transferred by radiation, $\sigma$ is Stefan-Boltzmann constant $\left(\sigma=5.670 \times 10^{-8} \mathrm{~W} \cdot \mathrm{m}^{-2} \cdot \mathrm{K}^{-4}\right)$ and $T_{1} / T_{2}$ are the temperatures of two bodies between which heat is transferred. Clearly $h_{r}$ is a strong function of temperature.

\subsection{Film Temperature $\left(T_{f}\right)$}

Another parameter known as film temperature $\left(T_{f}\right)$ defined as the temperature at which properties of air are determined for use in calculations of HTCs, is given by [3]

$$
T_{f}=\frac{1}{2}\left(T+T_{\infty}\right)
$$

where $T=\bar{T}$ and $T=T_{s}$ during the phases in which heat is transferred by free convection and radiation from top surface and surface of heated mold walls, respectively.

\subsection{Determination of Thermal Resistance $\left(R_{t}\right)$}

Thermal resistance of mold material is another important parameter, which contributes towards overall rate of heat transfer during conduction. Though very high, it is a strong function of temperature and keeps on changing with change of temperature. Thermal resistance of composite wall made up of finite small layers of materials of different thermal resistances may be written as [15]

$$
R_{t}=\frac{L}{k A}
$$

where, $L$ is the thickness of mold wall. $A$ is the surface area of mold exposed to heat and acting as thermal resistance and $k$ is the overall thermal conductivity of composite mold wall made up of different materials.

As the mold is made up of layers of refractory materials, which individually have their own thermal conductivities, thus overall thermal conductivity could be calculated only if effect of all layers is taken into account. Thus, temperature dependent expression for thermal conductivities may be written as [5] [20]

$$
\begin{aligned}
& k=0.60401-0.76723 \times 10^{-3} T+0.79544 \times 10^{-6} T^{2} \quad(20-30 \text { mesh size sand }) \\
& k=0.67570-0.79335 \times 10^{-3} T+0.55621 \times 10^{-6} T^{2} \quad(40-70 \text { mesh size sand }) \\
& k=0.33271-0.16762 \times 10^{-3} T+0.17580 \times 10^{-6} T^{2} \quad(70-100 \text { mesh size sand })
\end{aligned}
$$

Their effect is incorporated based upon numbers of layers formed by each mesh sand in the final mold wall. The overall thermal conductivity is then subs- 
tituted in Equation (29) to get overall thermal resistance which the mold walls offer to the flow of heat. It is evident that thermal conductivities are strong function of temperature and keeps on changing with change in temperature.

\section{Simulation Using Object-Oriented Technique}

The model for calculating time of solidification was programmed in an object-oriented programming language $\mathrm{C}++$. The iterative approach was adopted in which resultant value reports back to its initial value thus generating iterative loop, which yield the results in more effective way (i.e. keeps record of changes occurring in small increments) by convergence. The Borland $\mathrm{C}++3.1$ package was used for programming. All variables were first given certain symbol and that symbol was defined in float number format as functions. These user-defined functions are then used throughout the program. Program asks about different variables as inputs and then computes the results using predefined functions and formulas in $\mathrm{C}++$ output window. Time is declared and defined as controlling function in the program upon which all values depend. Each calculated value reiterates itself using time as parameter yielding final result as a progression/summation of small incremental results. Program first asks about an assumed value of time of solidification and then asks about values of constants. These are used from literature [3] [15] [18]. The value of time is asked in order to calculate incremental heat losses and use the data back into equations to get actual results. Final time of solidification is determined when assumed value of time matches or becomes nearly equal to calculated value (this is the time at which metal completely solidifies). Other user input values are entered in the program to automatically generate the results (see Table 1 ).

A unique feature of program is that it can work for almost all types of metals and mold materials with 8 coatings ( 6 coatings of 20 - 30 mesh sand, 1 coating of $50-70$ mesh sand and 1 coating of $70-100$ mesh sand). It specifically takes the effect of mold heating into consideration (aim of present study) while calculating time of solidification and gives behavior of castings with preheated molds. The program also displays different auxiliary information such as amounts of heat released by convection, conduction and radiation, heat left in metal and change of thermal conductivity of mold materials with time and temperature.

Table 1. Model parameter values for simulation [21] [22] [23] [24].

\begin{tabular}{ccccc}
\hline Sr. No. & Parameter & Description & Units & Value \\
\hline 1 & $\rho$ & Density of metal & $\mathrm{kg} / \mathrm{m}^{3}$ & 8912 \\
2 & $\varepsilon$ & Emissivity of molten metal & $\mathrm{Nil}$ & 0.19 \\
3 & $\varepsilon$ & Emissivity of mold material & $\mathrm{Nil}$ & 0.78 \\
4 & $C_{p}$ & Specific heat of metal & $\mathrm{J} / \mathrm{kg} / \mathrm{K}$ & 730 \\
5 & $H_{f}$ & Heat of fusion of metal & $\mathrm{J} / \mathrm{kg}$ & 174,700 \\
6 & $\sigma$ & Stefan - Boltzmann constant & $\mathrm{W} / \mathrm{m}^{2} / \mathrm{K}^{4}$ & $5.670 \times 10^{-8}$ \\
\hline
\end{tabular}


The data obtained from $\mathrm{C}++$ model is plotted in the form of graphs and then those graphs are compared with graphs obtained by plotting actual thermocouple readings in experiment. They are found in good agreement.

\section{Experimental Procedure}

Experimental setup consists of an investment casting shell made of silica with zircon prime coat in which twenty simple cubical shape pieces were connected to a central rod (down sprue) (Figure 1).

Shell is made up of approximately $20 \mathrm{~mm}$ thick composite wall consisting of three layers of sand namely 6 layers of 20 - 30 mesh sand, 1 layer of $50-70$ mesh sand and 1 layer of $70-100$ mesh sand layer (backing layer). Downsprue was $225 \mathrm{~mm}$ long rod of $40 \mathrm{~mm}^{2}$ cross-section. A pouring basin was left on the top of tree to allow the molten metal to go down to the mold. Two thermocouples were connected to shell as shown (Figure 2).

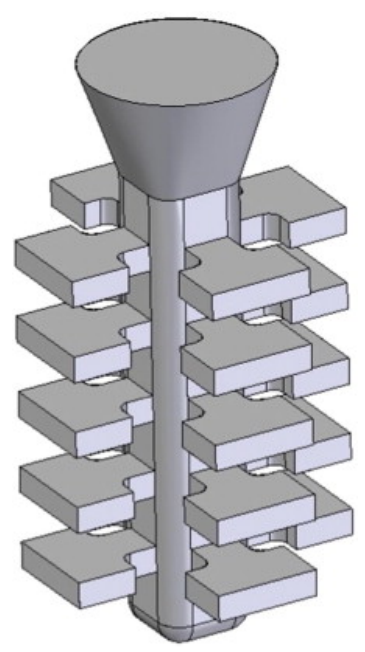

Figure 1. Schematic of Investment casting tree.

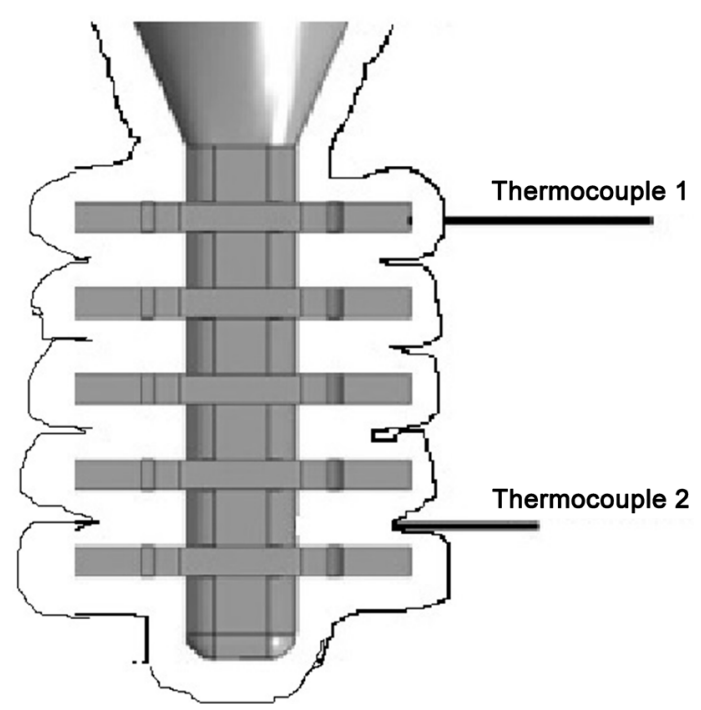

Figure 2. Schematic of thermocouples connected to shell. 
Metal used was pure iron superheated to temperature of $1620^{\circ} \mathrm{C}$. Metal was melted in magnesia crucible in an induction furnace. Mold temperature was raised slowly at a rate of $25^{\circ} \mathrm{C} / \mathrm{min}$ to $550^{\circ} \mathrm{C}$. When metal was poured in sprue it quickly goes to bottom of mold and gets distributed in cubes through ingates. It quickly started solidifying there and temperature of metal started decreasing while that of mold started increasing. Temperature was measured from pyrometer and thermocouples while time is measured from stopwatch. Already heated mold assists in reducing the thermal sock that mold material had to bear if poured in cold state thus avoiding solidification defects at the same time keep mold integrity. This process continued up to a certain limit till which metal losses all its sensible heat. After this, temperature drop became steady and further loss of heat occurred in the form of loss of heat of fusion of metal. Temperature of metal remained steady at its melting temperature from this point onwards and no decrease in temperature is observed. However, metal continued to lose all its heat till all of metal get solidified. This occurred at the melting point of metal which by far is above the temperature till which mold is heated (approximately two times higher) but still mold heating helps in reducing many problems which may arise as a result of cold pouring specially of metals with large alloying content. After this, solidified metal cools as a whole and has no affect towards development of initial solidification defects apart from shrinkage which is effectively countered by mold heating. Should there be no mold heating, surface of metal cools down way more rapidly than inner and liquid pool accumulated on top gets thinner quickly and becomes inefficient to feed the shrinking metal. Mold heating keeps the mold temperature high for longer periods of time and reduces the rate of heat transfer from hot metal to cold wall along with mold capping materials and reduces shrinkage. Time taken up to this point is known as total time of solidification. The readings of thermocouples and pyrometer were then plotted in the form of graphs and compared with graphs obtained from simulation of solidification to verify the validity of model.

\section{Results and Discussion}

Results consisted of reading of thermocouples from experiment and outputs from simulations represented in the form of plots over a range of data. The primary aim is to determine the process parameters and check the validity of model. These observations primarily show transient (time dependent) behavior of heat transfer phenomena and determine the conditions of casting at different intervals of time as affected by external mold heating which was not performed previously [9] [10] [14]. The readings were taken at small intervals of time to get better representation of thermal heat transfer pattern across mold surface.

Both simulation and experimental results are in agreement with each other, and almost similar time dependent heat transfer patterns are exhibited till the point where all the heat of metal is lost, and complete solidification occurs. The model also shows the effect of time and temperature on different properties of 
mold material as well as gives heat transfer pattern across mold wall with change of processing conditions. It also takes into account the dynamic change in heat transfer coefficients with time along with change in quantities of heat(s) released as affected by change of metal and mold temperature (presently aimed) and amount of incipient heat left behind in a given amount of metal as a result of heat transfer.

\subsection{Effect on Resistance Heating Elements}

As discussed earlier (Section 2.1.1), heat transfer of whole process is started initially by heating of resistance heating elements. Heating elements gets heated as a function of time. When temperature of heating element is plotted as a function of time, a graph shown in Figure 3 is obtained.

This figure shows that, metal of heating elements is initially at room temperature. As the power is increased to heating elements, the temperature at their surface starts rising. This rise is not linear but shows somewhat exponential behavior which is evident from previous studies and observations as well [25]. This happens due to excitation, vibrational and rotational motion of atoms of elements of material of heating unit. As the metal gets heated, more and more atoms get excited, collide with each other resulting in more lattice vibrations and eventually exponential rise in temperature. This temperature rise becomes steady after reaching a peak value at which energy generated by motion of atoms is balanced by heat input to system thus a balance is reached at which no further rise of temperature occurs. However, even after reaching their peak value of temperature, heating elements keeps on squirming about their mean value. This is another interesting phenomenon. There are two compelling reasons for this.

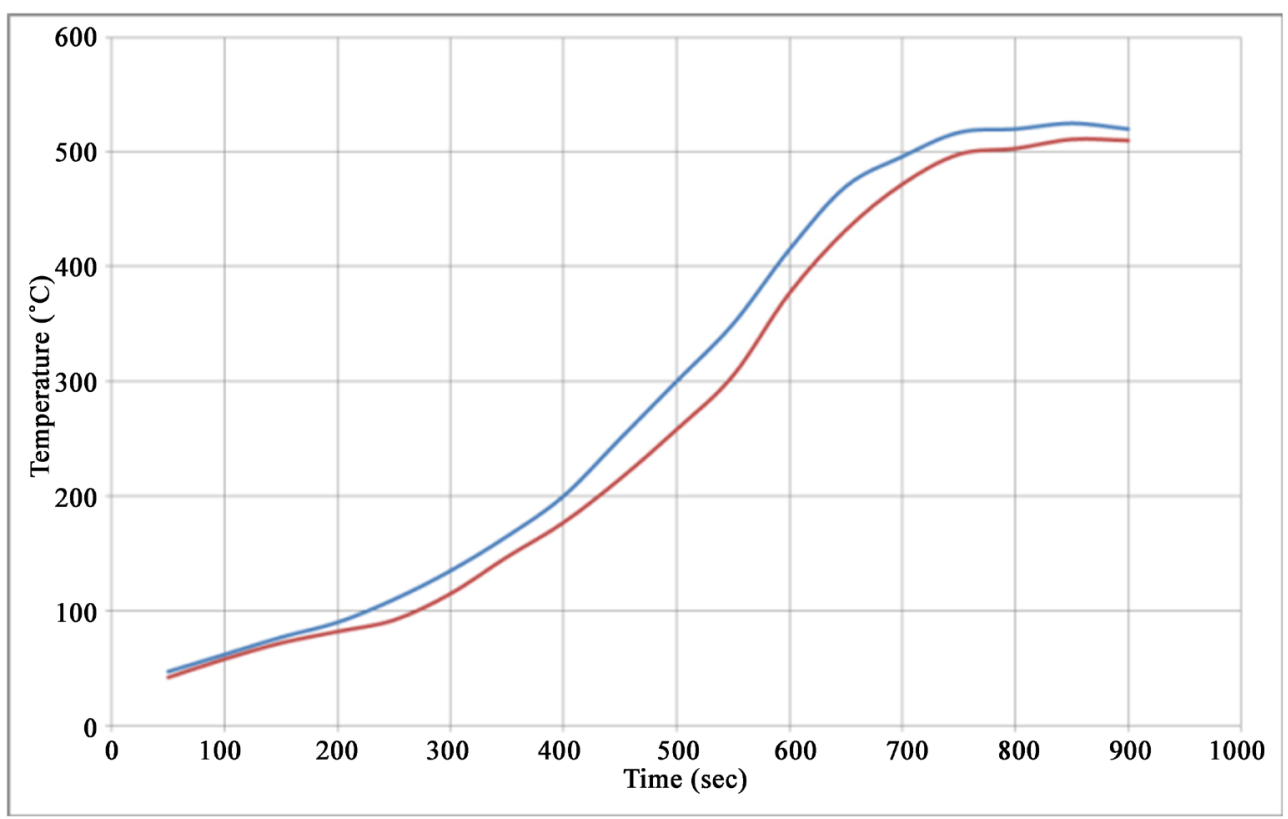

Figure 3. Plot of simulated and mold surface thermocouple readings as a function of time (Red: experimental results, Blue: simulated results). 
First, controller which is responsible for maintaining the temperature of heating elements shuts off and then turns back on instantaneously due to coding. This is the reason of small but continuous rise and fall of temperature at maximum peak value of temperature. Second reason again lies in atomic structure of material. The crystal structure of material of heating element (Nichrome wire) is a typical metal lattice with metallic bond tying up atoms at (assumed) fixed positions at the corners of regular well defined lattice [26]. While it is possible to observe vibrational rotation of their atoms, however, primarily after reaching peak value of temperature, the lattice vibration is restricted by the very tight fix geometry of metallic lattice which offers intrinsic resistance to even very feeble motions. These two factors are assumed to account for attainment of steady state of temperature of heating elements at their peak temperature value. Finally, curve of time and temperature obtained from experimental values (thermocouple inserted - red line) have less sharp slope as compared to simulation results (blue line) and lies significantly beneath it. This happens because in actual practice there are many factors which do not account for the rapid rise of temperature. In fact, heat keeps on getting extracted from surface of heating elements more sharply due to various other practical mechanisms of heat transfer (e-g. heat dissipation to free space, quenching of space/environment around heating elements due to low temperature in the chamber of furnace as a result of circulation of cooling water, condensation at chamber walls and effect of vacuum itself). All these contribute to over increase in rate of heat transfer.

\subsection{Effect of Preheated Mold on System Variables}

Various system variables and heat transfer patterns in and around them are affected by conditions of mold, its temperature profile and temperature of heating elements. These are directly affected by any change/fluctuations in mold temperature which directly affect overall system efficiency. These are explained in detail one by one.

\subsubsection{Rate of Decrease of Metal Temperature}

When instantaneous reading of pyrometer made to impinge the liquid metal surface is plotted against time a graph shown in Figure 4 is obtained.

This is typical plot which describes the heat dissipation pattern from liquid metal to its surrounding once it is made to fall in cold mold. Contrary to anticipation and general belief, the rate by which metal loses its temperature is not constant rather it is a function of constantly changing (transient) and evolving heat transfer conditions itself. The greater the gradient of metal and mold temperature, the higher the change of rate of heat transfer from metal to surrounding. This is very difficult to control and observe factor especially when rate of change of heat transfer itself is not constant. However, it has large implications on the performance of part and system. This change in rate of heat transfer can cause incipient thermal fluctuations and generate stresses inside the body of system which is extremely detrimental to part performance and severely affect its 


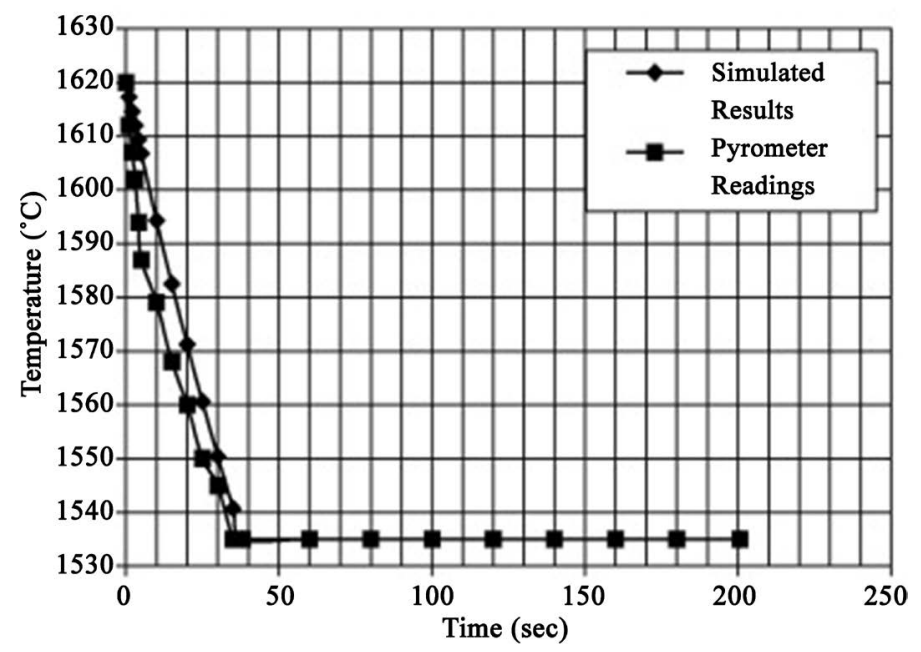

Figure 4. Experimental and simulated hot metal temperature profile in cold mold as a function of time.

creep properties. This factor must be taken into account and taken care of in the design of thin section castings having large number of protrusions, contours and sharp changes in cross sections (e-g turbine blades, aero foils, electronic heat sinks and heat exchanger fins). A higher mold temperature and its careful control can help reduce these stresses and generate a smooth temperature profile which not only helps in improvement of mechanical properties but in case of solidifying metal become the source of fine grain structure, removal of segregation and other detrimental high temperature casting defects.

\subsubsection{Mold Surface Temperature}

Like rate of heat transfer, mold surface temperature is also a strong function of external mold preheating. It seems obvious that outside mold temperature would exactly be same as that of heating element. However, this assumption which is taken while designing the model is not entirely valid. In actual conditions, there is a lot of heat loss in places between heating element and mold surface. First, heating elements are not at all touching surface of ceramic shell mold. If it happens, it can result in immediate burnout, fusion, removal of any volatiles, binder and water and conversion of hard ceramic shell to amorphous powder which will fall off mold surface. Thus, this condition is deliberately avoided. Second, air gap in spaces between mold and heater serve the purpose of insulator and cause change of heat transfer coefficients (HTC) which affect heat transfer pattern. In practical situations an effort is made to keep the mold temperature at constant value irrespective of what is happening in surrounding. This is usually achieved by use of glass wool and other soft insulating materials which reduce/minimize the intricacies and crevices from where heat can escape. This helps in attainment of smooth heat transfer pattern which yield homogeneous mechanical properties and increase casting quality. A general plot describing time dependent temperature profile across mold wall as a result of pouring of hot metal in it is shown in Figure 5. 


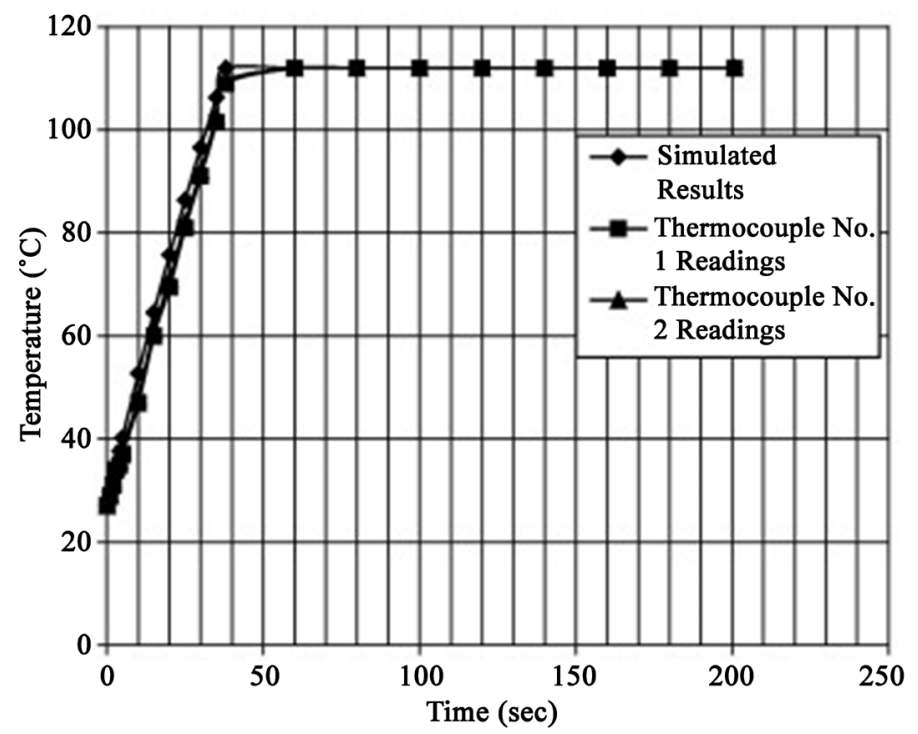

Figure 5. Effect of time on mold outer surface temperature (simulated and thermocouple readings).

This typically explains rapid heating of mold to high temperature as a result of heat generated from loss of superheat of metal. It explains the attainment of steady state once all super heat is extracted and metal starts losing its heat of fusion. Further, once this condition is reached rate of heat transfer is minimized, decrease in heat transfer capacity of heated mold itself because of unavailability of sink.

\subsubsection{Content of Heat (Released and Contained)}

Although not to an appreciable extent, external mold heating also influences quantity of heat released and contained in a casting at a certain instant of time. As reported previously [19], in an uncontrolled environment, various factors affect the heat transfer phenomenon, thus quantity of heat varies appreciably with the change of time as the temperature of metal decreases in a cold mold. The quenching effect from cold mold walls, convection currents caused by purged gas movement, quenching effect caused by vacuum itself, condensation at cold chamber walls (thus associated cooling) and finally phase transformations in mold material are all the factors which contribute towards overall rate of heat transfer and hence quantity of heat consumed and retained after a certain period of time. A carefully controlled mold heating mechanism can effectively influence the heat distribution pattern in a mold cavity. In general, higher the mold heating lower will be the variation in the temperature distribution profile across cross section (thickness) of mold wall. However, this trend in not linear and deviations exist from ideal linear behavior due to fluctuations caused by intrinsic as well as extrinsic factors (as explained above). Detail effects of these factors are not considered here. This heat content released and contained in the metal are calculated from simulation in $\mathrm{C}++$ and represented in the form of a plot as shown in Figure 6(a) and Figure 6(b). These plots show almost near linear 

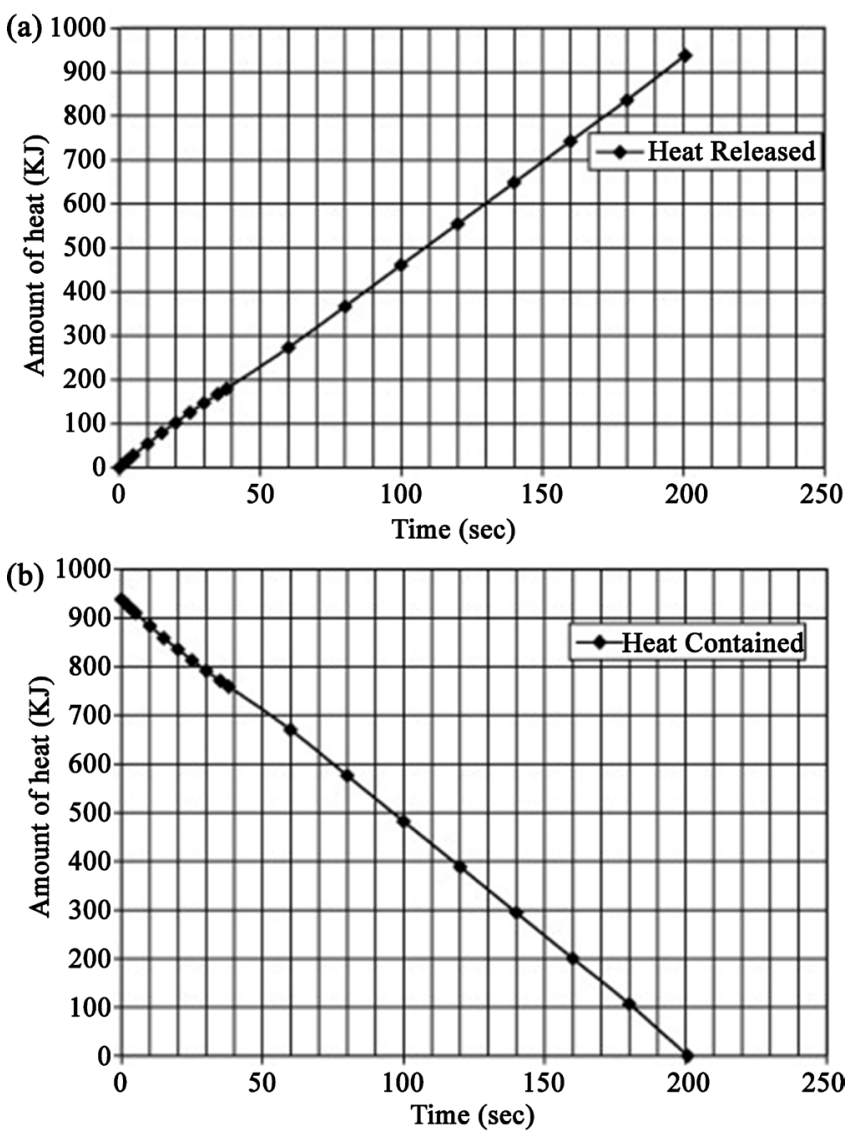

Figure 6. Effect of time on heat content of system (a) amount of heat released with time (b) amount of heat contained after time.

trends because of assumptions made and simplistic approach adopted here.

As can be observed, the variation in this quantity (not its distribution) is largely observed to follow a linear trend. Initially, when metal is hot and just poured in the mold it contains maximum amount of heat. This heat content is equal to super heat plus heat of fusion $\left(\mathrm{H}_{f}\right)$ in metal. As the time passes and metal begins to cool down in the mold it starts losing its heat through different modes of heat transfer subsequently losing its heat content. Lost heat content starts going to mold and mold temperature starts rising which is complemented by external mold heating. The time up to which metal losses all its heat (both super heat and heat of fusion) is known as time of solidification, which could be clearly marked on the graphs, which again is a validity of the model. The significance of mold heating in this whole process is to control quantity of heat and use it as much as possible to increase, control and enhance system efficiency. In practical situations a time loop iteration based controller is employed which reports back instantaneous values of temperature from metal and mold to their initial values and subsequently adjusts the heating elements to such an extent that power factor is reduced and system efficiency is enhanced. Modern furnaces supplied by large corporations e-g Nobertherm ${ }^{\circledR}$ have purpose-built controller of this type installed in their units which have proved to impart a lot savings of 
capital and running costs.

\subsubsection{Thermal Resistance and Conductance of Mold}

As other intrinsic properties of mold are affected by external mold heating, similarly thermal resistance of mold itself are also strong function of any change in heat (internally or externally). Any feeble change in thermal profile around the mold has severe impact on its ability to conduct or resists heat. Again, this happens due to tangible and non-tangible reasons. Former being positioning of mold in the casting cavity (sand casting), shape of mold (permanent or disposable), associated geometry (investment casting) and auxiliaries around it while later factors include; type of material, its quantity, internal crystal structure, type of lattice, lattice defects, their distribution and variation. Both these are very sensitive to change in temperature. In general, a smooth and controlled increase in temperature will cause a gradual rise of thermal resistivity in ceramics while it results in decrease of thermal resistivity in metals. In ceramics, increase in thermal resistivity is manifested by restricted motion of atoms in ceramic lattice. Since ceramics are oxides, nitrides or borides which consists of large atoms arranged in close packed symmetry, rise in temperature creates a lot of hindrance to flow of heat through these close packed symmetries. In an uncontrolled scenario (no external mold heating), ceramic shell resistance increases to certain value at which it becomes constant due to arrest point associated with solidification of metal (Figure 7).

However, these arrest points are not always beneficial. A careful adjustment and control of heat transfer pattern by the help of control of external mold heat temperature can result in avoidance of thermal shocks which mold material experience at these arrest points. This is beneficial for long service life and quality of casting. A casting without inherent thermal and mechanical stresses does not need post processing heat treatment and can serve better in service life without incurring additional cost for removal of stresses [1]. In practical situations, effort

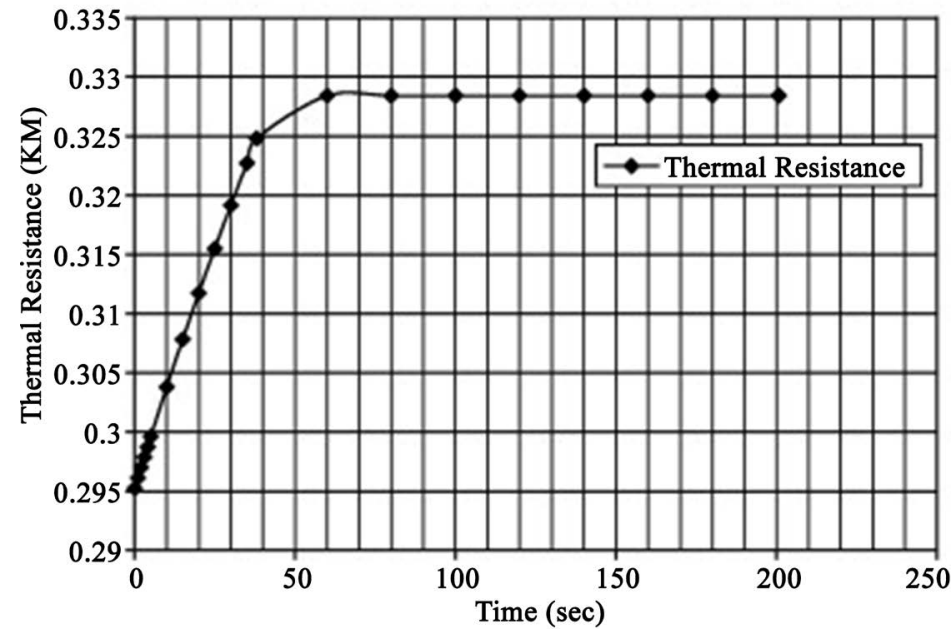

Figure 7. Thermal resistance profile of mold material as function of time with decreasing temperature. 
is made to keep this rise of thermal resistance to a minimum as it prolongs the time in which solidification should occur. An effective way to achieve this may be is the use of water sprinkling on the external faces of large size cast iron metallic molds which increase the rate of heat transfer thus minimize accumulation of heat and increase of resistivity (a fairly common practice in large scale iron and steel foundries). Another method may be is the installation of chills in complex, intricate small size castings. These chills (usually of copper) serve same purpose of increasing the rate of heat transfer from areas which are prone to accumulation of metal during filling (also known as dead zones in fluid mechanics [17]) and thus can become potential dangerous zones. In this case mold heating is ineffective for achieving fine grain size and strong, homogeneous castings.

\subsubsection{Holding Time}

Finally, last but not least most important parameter which is directly influenced by mold heat is the holding time till which metal get heated and then stays to ensure homogenization in chemical composition and attainment of uniform temperature profile such that casting defects caused by improper distribution may be avoided. Under normal, uncontrolled conditions, this holding time is small to intermediate. Any effort to increase the ability of mold/crucible to keep metal at high temperature for a long time can cause severe problems for its long-term functioning and service life. This happen because a huge temperature difference exists between inner and outer surface temperature of mold which is reason for creation of thermal stresses leading towards crack formation. External mold heating can minimize this gap and help attain a condition where outer surface of mold may not be at room temperature which is helpful to avoid cracks, tears and fissure formation in cold outer walls. A numerically controlled heater keeps on switching ON and OFF to keep outer surface temperature to constant/near constant value. This is possible by employing mold heater. Usually in practice, they are employed in various geometries/formations, but still their most common and effective formation is placement of continuous coil all along the vertical side (walls) of mold which should be able to heat quickly and keep whole internal body to a constant desired temperature. The routine practice in large castings in industry is employment of separate mold heater (as a standalone furnace) which is used to heat mold to a desired temperature externally before loading it to actual vacuum induction/arc melting furnace chamber. This practice can not only save time but offers the possibility to exercise a lot of cost reduction by avoiding heating of mold using heating elements in the mold cavity with integrated furnace unit. An additional external standalone furnace is proposed for use prior actual loading of heated mold in integrated furnace chamber for pouring. In this situation, mold heating elements inside integrated furnace are not fully used.

\section{Conclusions}

This work leads to following conclusions based upon experimentation and simula- 
tion to determine the effect of mold heating on properties of investment castings.

1) Change, variation and evolution of HTCs with intrinsic (specific heat, latent heat capacity, heat of fusion) and extrinsic (shape, size, weight and dimensions of casting) properties of system refine original calculations, ascertain their true value and enhance accuracy.

2) Use of proper HTCs and their incorporation back into original values help in bringing simulated mold surface thermocouple readings to actual readings and improve overall process efficiency by $90 \%$.

3) Heat transfer patterns are strong function of physical geometry and configuration of mold. Arrangement of various components (downsprue, runner, vents, gating system $\&$ risers) during the casting process with respect to cast material properties plays a critical role on the heat transfer process. Careful design of these components can give more precise control over the overall heat transfer system.

4) Heat transfer patterns are also a strong function of molding materials. Primary facing and backing sand layers, type of sand used in them and number of each layers forming overall mold wall has a significant effect on thermal properties as well as heat transfer pattern of the system (Higher wall thickness in general retards heat transfer).

5) Solidification time also strongly depends on type and quantity of metal being cast. A metal of intrinsic higher value of melting point will stay liquid for a long period of time. Similarly, large amount of metal will contain high quantity of heat which again can keep metal liquid for long period of time. For example, large castings take long time to solidify as compared to casting with thin profiles and small section thickness.

All the above factors contribute towards overall time of solidification, heat transfer coefficients (HTC) and pattern of transfer of heat in castings. Any change and/or variation in these should be taken into account while designing a successful investment casting process as well modeling and simulating of heat transfer phenomena in it.

\section{Dedication and Acknowledgements}

Authors would like to acknowledge the selfless untiring support and help of, and would like to dedicate this work to Mr. Bilal Saleem (late) (1982-2015) who was Assistant Manager at Steel Castings (Pvt.) Ltd. Gujranwala during the time these experiments were performed. Without his efforts, interest and motivation this work would have never accomplished.

\section{Conflicts of Interest}

The authors declare no conflicts of interest regarding the publication of this paper.

\section{References}

[1] Taylor, H.F., Flemings, M.C. and Wulff, J. (1962) Foundry Engineering. John Wiley and Sons, Hoboken. 
[2] Heine, R.W., Loper, C.R. and Rosenthal, P.C. (1967) Principles of Metal Casting. McGraw-Hill, Boston.

[3] Poirier, D.R. and Poirier, E.J. (1998) Heat Transfer Fundamentals for Metal Casting, with SI Units. Wiley, Hoboken.

[4] Sabau, A. (2005) Numerical Simulation of the Investment Casting Process. Transactions of American Foundry Society, 113, 407-417.

[5] Pehlke, R.D., Jeyarajan, A. and Wada, H. (1982) Summary of Thermal Properties for Casting Alloys and Mold Materials. NASA STI/Recon Technical Report N, 83.

[6] Sabau, A.S. and Viswanathan, S. (2004) Thermophysical Properties of Zircon and Fused Silica-Based Shells Used in the Investment Casting Process. Transactions of the American Foundry Society, 112, 4-81.

[7] Gebelin, J.-C. and Jolly, M.R. (2003) Modelling of the Investment Casting Process. Journal of Materials Processing Technology, 135, 291-300. https://doi.org/10.1016/S0924-0136(02)00860-9

[8] Givler, R.C. and Saylors, D.B. (2000) Efficient Runner Networks for Investment Castings. International Journal for Numerical Methods in Engineering, 48, 1601-1614. https://doi.org/10.1002/1097-0207(20000820)48:11<1601::AID-NME894>3.0.CO;2-0

[9] Upadhya, G.K., et al. (1995) Modelling the Investment Casting Process: A Novel Approach for View Factor Calculations and Defect Prediction. Applied Mathematical Modelling, 19, 354-362. https://doi.org/10.1016/0307-904X(95)90001-O

[10] Konrad, C.H., et al. (2011) Determination of Heat Transfer Coefficient and Ceramic Mold Material Parameters for Alloy IN738LC Investment Castings. Journal of Materials Processing Technology, 211, 181-186.

https://doi.org/10.1016/j.jmatprotec.2010.08.031

[11] Dong, Y., et al. (2011) Determination of Interfacial Heat-Transfer Coefficient during Investment-Casting Process of Single-Crystal Blades. Journal of Materials Processing Technology, 211, 2123-2131. https://doi.org/10.1016/j.jmatprotec.2011.07.012

[12] O’Mahoney, D. and Browne, D.J. (2000) Use of Experiment and an Inverse Method to Study Interface Heat Transfer during Solidification in the Investment Casting Process. Experimental Thermal and Fluid Science, 22, 111-122. https://doi.org/10.1016/S0894-1777(00)00014-5

[13] Zhang, X.P., Xiong, S.M. and Xu, Q.Y. (2006) Numerical Methods to Improve the Computational Efficiency of Solidification Simulation for the Investment Casting Process. Journal of Materials Processing Technology, 173, 70-74. https://doi.org/10.1016/j.jmatprotec.2005.09.030

[14] Anderson, J.T., Gethin, D.T. and Lewis, R.W. (1997) Experimental Investigation and Numerical Simulation in Investment Casting. International Journal of Cast Metals Research, 9, 285-293. https://doi.org/10.1080/13640461.1997.11819670

[15] Holman, J.P. (2002) Heat Transfer. McGraw-Hill, Boston.

[16] Hughes, E., et al. (2016) Hughes Electrical and Electronic Technology. Pearson Education Limited, London.

[17] Çengel, Y.A. and Boles, M.A. (2014) Thermodynamics: An Engineering Approach. McGraw-Hill Education, New York.

[18] Bergman, T.L., Lavine, A.S. and Incropera, F.P. (2011) Fundamentals of Heat and Mass Transfer. 7th Edition, John Wiley \& Sons, Incorporated, Hoboken.

[19] Rafique, M.M.A. and Iqbal, J. (2009) Modeling and Simulation of Heat Transfer 
Phenomena during Investment Casting. International Journal of Heat and Mass Transfer, 52, 2132-2139. https://doi.org/10.1016/j.ijheatmasstransfer.2008.11.007

[20] Yuan, C., et al. (2015) Investment Casting of Ti-46Al-8Nb-1B Alloy Using Moulds with $\mathrm{CaO}$-Stabilized Zirconia Face Coat at Various Mould Pre-Heat Temperatures. Ceramics International, 41, 4129-4139.

https://doi.org/10.1016/j.ceramint.2014.11.109

[21] Takehiko, I., et al. (2012) Spectral Emissivity Measurements of Liquid Refractory Metals by Spectrometers Combined with an Electrostatic Levitator. Measurement Science and Technology, 23, 125602. https://doi.org/10.1088/0957-0233/23/12/125602

[22] Burgess, G.K. and Waltenberg, R.G. (1915) The Emissivity of Metals and Oxides. US Government Printing Office, Washington, DC.

https://doi.org/10.6028/bulletin.264

[23] Burgess, G.K. and Foote, P.D. (1914) The Emissivity of Metals and Oxides. I: Nickel Oxide (NiO) in the Range 600 to $1300^{\circ}$ C. Physical Review, 3, 494. https://doi.org/10.1103/PhysRev.3.494.2

[24] Hixson, R.S., Winkler, M.A. and Hodgdon, M.L. (1990) Sound Speed and Thermophysical Properties of Liquid Iron and Nickel. Physical Review B, 42, 6485-6491. https://doi.org/10.1103/PhysRevB.42.6485

[25] Theraja, A.K. (2016) Textbook of Electrical Technology. S Chand \& Company Limited, New Delhi.

[26] Cullity, B.D. and Stock, S.R. (2001) Elements of X-Ray Diffraction. Prentice Hall, Upper Saddle River. 